\title{
Travma Sonrası Stres Bozukluğu İçin EMDR: Bir Olgu Sunumu
}

\author{
Sezen SAĞLAM ${ }^{1}$, Özlem ŞENER ${ }^{2}$
}

Özet: Travma sonrası stres bozukluğu, travmatik olayı tekrar tekrar yaşama, aşırı uyarılmışlık hali ve travmayla ilişkili uyaranlardan kaçınma şeklinde görülen, travma sonrasında gelişen bir ruhsal bozukluktur. EMDR, ise farklı psikoterapi yaklaşımlarının öğelerini kapsayan, standartlaştırılmış tedavi prosedürleri bulunan, bütüncül bir psikoterapi yöntemidir. Bu çalışmada EMDR tedavi yönteminin travma sonrası stres bozukluğu belirtilerinin tedavisinde etkili, güçlü ve kısa süreli bir terapi yöntemi olduğu, ilişki sorunlarının travma sonrası stres bozukluğu belirtileri ürettiği ve aldatılma sonrasında beş aydır travma sonrası stres bozukluğu belirtileri gösteren bir olgunun tedavi süreci ele alınmıştır. Araştırmanın sonunda yapılan tedavinin başarılı olduğu tespit edilmiştir. Ayrıca EMDR tedavi sürecinde travmatik yaşantıya dair rahatsız eden sahnelerin ve tetikleyicilerin çalışılmasının \%80 oranında travma sonrası stres bozukluğu belirtilerinin ortadan kalkmasında etkili olduğu, danışanın erken çocukluk dönemine ait olumsuz yaşantılarının çalışılması sonucunda belirtilerin tamamen ortadan kalktığı görülmüştür.

Anahtar Kelimeler: EMDR, romantik ilişkiler, aldatma, travma sonrası stres bozukluğu.

\section{EMDR For Post-Traumatic Stress Disorder: A Case Report}

\begin{abstract}
Post-traumatic stress disorder is a post-traumatic mental disorder that occurs as a recurrent traumatic event, overstimulation and avoidance of trauma-related stimuli. EMDR is a holistic method of psychotherapy with standardized treatment procedures covering elements of different psychotherapy approaches. In this study, it is explained that EMDR therapy is an effective, powerful and short term therapy method in the treatment of post-traumatic stress disorder symptoms, relationship problems produce post-traumatic stress disorder symptoms and how to treat a patient with post-traumatic stress disorder symptoms for five months after being deceived. At the end of the study EMDR treatment was successful for this case. In addition, it was reported that $80 \%$ of the study of the disturbing scenes and triggers related to the traumatic experience was effective in the elimination of post-traumatic stress disorder symptoms and that the symptoms disappeared as a result of studying the negative experiences of the early childhood.
\end{abstract}

Keywords: EMDR, Romantic relationships, cheating, posttraumatic stress disorder.

\footnotetext{
${ }^{1}$ Orcid ID: https://orcid.org/0000-0003-2503-7929, Uzm. Klinik Psk. Sezen Sağlam, İstanbul Aydın Üniversitesi, İstanbul-Türkiye, sezensaglam@stu.aydin.edu.tr

${ }^{2}$ Orcid ID: https://orcid.org/ 0000-0002-0081-7374, Dr. Öğr. Üyesi, Özlem Şener, İstanbul Aydın Üniversitesi Eğitim Fakültesi, Eğitim Bilimleri Bölümü, İstanbul-Türkiye, ozlemsener@aydin.edu.tr
} 


\section{Summary}

Psychologic trauma is a mental wound. Many events in life can lead people to be mentally wounded and traumatized. Yet, not everyone who experiences a traumatic event develops post traumatic stress disorder (PTSD) (Hasanoğlu, 2018). PTSD is a psychological disorder which develops after a trauma that causes to be repeatedly remembered of an experienced traumatic event, to flash some scenes pertaining to the event before the person's eyes like a film strip, high levels of anxiety and stress, nightmares related to the traumatic event, an intense, emotional feeling, and feelings such as desperation and dismay (Hasanoğlu, 2018).

It has been known that the effects of traumas caused by people are greater than the effects caused by natural disasters in the process of developing post traumatic stress disorder. (Özgen ve Aydın, 1999). Traumas that caused by people, the guilt, inefficacy, insignificancy and worthlessness that the traumatized person feels after the traumatic event, deeply affect the person's perception on other people and the world, expectations and relationships deeply (Hasanoğlu, 2018). Trauma is devastating for people of all ages. These marks that make a huge destruction in mental health should be cured in order not to cause permanent mental damage and one of the psychological treatment methods that is applied for this is Eye Movement Desensitization and Reprocessing (EMDR) Method.

EMDR was discovered by Francine Shapiro in 1987, and with controlled studies on people who experienced traumas (Saphiro, 2018). EMDR is applied in the manner of handling the traumatic memory, negative beliefs, emotions and physical senses caused by the traumatic memory and bilateral eye movements or bilateral stimulations (voice, touching) together. It is stated that people who demonstrates the symptoms of post traumatic stress disorder cannot realize that the traumatic event they experienced was in the past and they see it as a threatening event affecting the time being and the future (Ehlers ve Clark 2000). The main aim of EMDR is to process the negative experiences and realize the transition of the client from the past to the present (Kavakçı, 2014; Shapiro, 2017).

According to other psychotherapy methods, it is reported that after three to five sessions with the EMDR method that reduce the symptoms of PTSD faster (Kavakçı, 2014), PTSD reactions has been reduced by $77-100 \%$. Within the scope of this research, the application of EMDR on the case that revolves around PTSD experience is discussed. In the research, a case study that shows PTSD symptoms after being cheated on is investigated.

Case Features: Ms. Y is a 37-years-old woman, doctor, married for ten years, mother of two children and lives in Istanbul. Her appearance and personal grooming is at medium level. She makes eye contact, is angry, talks loudly and mostly cries. She appears to be in sorrow and to be depressed. She learns that she was cheated five months ago by her spouse. Due to devastating situation created by being cheated, she seeks psychological support.

Case Report: The interviews with the client took place in a private psychological counseling center during the year 2019. EMDR therapy method was applied within the scope of research in 5 sessions of the interview totaling 10 sessions overall. The records of the interview do not contain any personal information of the client and the client has given the permission and consent for the research to be published.

The main goal of the research is to investigate the effect of EMDR on PTSD that emerges after being cheated in a relationship. Recent studies show that experience during relationship problems brings about a good deal of PTSD symptoms (Saphiro, 2018; p.16). In this study, it has been observed that Ms. Y, who was cheated by her spouse, demonstrated post trauma stress disorder effects such as sleep problems, nightmares, loss of appetite, intolerance, overreacting to stimuli, anger, crying spells, forgetfulness. According to the findings of this case, a drastic recovery has been observed in terms of the post trauma reactions of the case after applying EMDR method.

Ms. Y perceived this traumatic experience as a psychological abuse. Besides, it has been observed that the client had negative beliefs such as "I'm worthless", "I'm weak", "I don't have the control" about the scenes that flashed before her eyes and with applying EMDR therapy method, aforementioned beliefs were reprocessed and converted into positive beliefs. In the EMDR sessions, when studied on a memory which 
belongs to a traumatic life, other memories related to it are expected to be affected positively and discomfort levels can decrease per se. In this case, it has been observed that after studying on the first and the second memory, third one's discomfort level decreased to 5 which was previously measured 9 . EMDR method has been applied for flashing scenes and stimuli that repeatedly reminded of the event pertaining to the negative experience of the client for 10 sessions in total. It has also been observed that after EMDR sessions, PTSD symptoms that the client demonstrated after being cheated for 5 months were reduced by $80 \%$. Literature researches state that PTSD symptoms recover at the rate of $77-100 \%$ after 3 to 5 sessions of EMDR application (Shapiro, 2017).

Indubitably, getting one good result on one case does not make it possible to deduce that EMDR is an effective method in all treatments of PTSD that is shown after being cheated. More researches supporting this field should be done. According to literature searches, there has not been any other study that supports this was encountered. Not only does this shows that this study is an unprecedented one, it also shows the need of more studies in this field. In spite of these limitations, this successfully conducted study is thought to pave the way for researchers of other fields. In conclusion, this study has shown that EMDR treatment is a good option as it is an effective, potent and short term method while studying PTSD.

Keywords: EMDR, Romantic releationships, cheating, posttraumatic stress disorder. 


\section{GÍRIŞ}

Psikolojik travma, ruhsal yaralanmadır. Yaşanılan birçok olay insanın ruhsal anlamda yaralanıp, travmatize olması için yeterlidir. Fakat her travmatik olay yaşayan kişi travma sonrası stres bozukluğu geliştirmemektedir (Hasanoğlu, 2018). Travma sonrası stres bozukluğu, yaşanmış olan travmatik olayın yineleyici bir şekilde devamlı hatırlanmasına, olayla ilgili bazı sahnelerin kişinin gözünün önünden film şeridi gibi geçmesine, kaygı ve stres düzeylerinin devamlı yüksek olmasına, yaşanılan travmatik olayla ilgili kabusların görülüyor olmasına, yoğun duygusal bir rahatsızlığın hissedilmesine, kişide çaresizlik, dehşet gibi duyguların hissedilmesine neden olan, travma sonrasında gelişen bir ruhsal bozukluktur (Hasanoğlu, 2018).

Toplumda ağır travmalara maruz kalmış insanların toplam sayıları bilinmemekle birlikte yapılan çalışmalar, insanların 3/1'inin yaşamları boyunca bir travmatik olaya maruz kaldığını ve \%1015'nde de travma sonrası stres bozukluğu belirtileri görüldügünü söylemektedir (EMDR Derneği, 2018). Travma sonrası stres bozukluğunun belirtileri, travmatik olayı tekrar tekrar yaşama, aşırı uyarılmışlık hali ve travmayla ilişkili uyaranlardan kaçınma şeklinde görülmektedir (Özgen ve Aydin, 1999).

Travma sonrası stres bozukluğu belirtilerinin ortaya çıkışını etkileyen risk faktörleri vardır. Bunlar kişinin kendine dair olumsuz inançları, geçmiş yaşam öyküleri, erken dönem travmaları, eğitim düzeyleri, yaşanılan travmatik olayın türü (insan eliyle veya doğal felaketler nedeniyle), şiddeti, süresi gibi etkenlerdir (Karaoğlu, 2016).

Travma sonrası stres bozukluğunun oluşmasında insan eliyle gerçekleşmiş travmaların etkisinin, doğal felaketler sonucunda gerçekleşmiş travmaların etkilerinden daha büyük olduğu bilinmektedir (Özgen ve Aydın, 1999). Özellikle insan eliyle yaşanan travmaları, travma sonrası stres bozukluğu açısından değerlendirdiğimizde, birey için artık dünyada öteki olan güvenilir değildir. Bunun sebebi olarak yaşanılan travmatik yaşantı sonrasında kişinin duyduğu suçluluk duyguları, yetersizlik ve değersizlik hisleri, bireyin bir diğer kişi ve dünya ile ilgili algılarını, beklentilerini, ilişkilerini derinden etkilediği görülmektedir (Hasanoğlu, 2018). Travma, kişi için her yaşta yıkıcıdır. Derin ruhsal yıkım yaratan bu izlerin kalıcı ruhsal hasarlara yol açmaması için iyileştirilmesi gerekmektedir ve bunun için uygulanan farklı terapi teknikleri vardır. Bunlardan biri de EMDR yöntemidir.

EMDR'nin açılımı (Eye Movement Desensitizationand Reprocessing) Göz Hareketleriyle Duyarsızlaştırma ve Yeniden İşleme'dir. 1987 yılında Francine Shapiro tarafından tesadüf bir şekilde keşfedilmiş olup, Shapiro’nun travma yaşamış kişiler üzerine yaptığı kontrollü çalışmalarıyla gelişmiştir (Shapiro, 2018). EMDR, farklı psikoterapi yaklaşımlarının öğelerini 
kapsayan, standartlaştırılmış tedavi prosedürleri bulunan, bütüncül ve etkili bir psikoterapi yöntemidir (Shapiro, 2017). EMDR'nin bugüne kadar iki milyon kişi üzerinde çalış1ldığı ve bu kişilerin başarılı bir şekilde tedavi edilmesini sağladığı bilinmektedir (EMDR Derneği, 2018).

EMDR tedavisi sekiz aşamadan oluşmaktadır. 1. Aşama: Danışan geçmişi, 2. Aşama: Hazırlık, 3. Aşama: Değerlendirme, 4. Aşama: Duyarsızlaştırma, 5. Aşama: Yerleştirme, 6. Aşama: Beden tarama, 7. Aşama: Kapanış (Tamamlama), 8. Aşama: Yeniden değerlendirme aşamalarıdır.

Her bir aşamanın kaç seans süreceği danışandan danışana değişiklik gösterir. İlk aşama danışanın öyküsünün alındığı ve tedavinin planlandığı evredir. İkinci aşama EMDR'nin anlatıldı̆̆ı, danışandan tedaviye dair izin alındığı ve danışanın seanslar içerisinde veya seanslar arasında yaşayabileceği rahatsılıklara karşı kullanabileceği stabilizasyon çalışmalarının yapıldığı hazırlık evresidir. Bu aşamada danışana EMDR ile ilgili olarak özet bir bilgi, teknik detaylar ile ilgili bilgi (mesafe, uyarı tipi, metafor), dur işareti, rahatlama, stabilizasyon teknikleri-güvenli yer gibi bilgiler aktarılarak beraber verimli bir çalışma ortamı sağlanır. Üçüncü aşama değerlendirme evresidir, bu evrede çalışılacak hedef anı belirlenir. Danışanın hedef anı hakkındaki rahatsızlık düzeyinin (Subjective Unit of Disturbance Scale = SUD), olumsuz bilişlerinin, hangi olumlu düşünceye sahip olmak istediğinin ve sahip olmak istediği olumlu bilişin geçerlilik düzeyinin (Validity of Cognition = VOC) sorulduğu evredir. Dördüncü evre çift yönlü uyarım ile duyarsızlaştırma işleminin yapıldığı evredir. Bu evrede SUD düzeyinin sıfır olmasına çalışılır. Danışanın rahatsızlık veren duyguları ele alınır ve uygun iç görüler ortaya çıkarılır. Beşinci evre, yerleştirme evresidir, ortaya çıkan yeni olumlu bilişin yerleştirilmesine çalışılır. Altıncı evre beden tarama evresidir. Rahatsızlık verici yaşantının anımsanmasıyla birlikte bedende rahatsız edici bir duyumun olup olmadığı kontrol edilir. Eğer var ise bedende bir gerginlik olmayana kadar çalışılır. Yedinci evre işlemenin yeterli olup olmadığının kontrol edildiği ve danışanın emniyetli bir şekilde seanstan ayrılmasının sağlandığı kapanış evresidir. Sekizinci aşama ise bir sonraki oturumda gerçekleştirilir, önceki seansta çalışılan anının hafta boyunca danışanın kendisini nasıl etkilediğinin sorulduğu izleme ve yeniden değerlendirme evresidir (Kavakçı, 2014; Shapiro, 2017).

EMDR travmatik anı ile bu anının oluşturduğu olumsuz inançlarla, duygularla ve bedensel duyumlarla, iki yönlü göz hareketlerinin ya da diğer iki yönlü uyarımların (ses, dokunma) kullanılması şeklinde çalışmaktadır. Travma sonrası stres bozukluğu belirtileri gösteren bireylerin yaşamış oldukları travmatik olayı geçmişte yaşanmış bir olay olarak değerlendiremedikleri ve bu olayı her an tehdit edici ve gelecek zamanı da etkileyen bir olay olarak algıladıkları belirtilmektedir (Ehlers ve Clark 2000). EMDR'nin birincil hedefi olumsuz yaşantıları işlemleyerek danışanın özgürce geçmiş zamandan şimdiki zamana geçişini sağlamaktır (Kavakçı, 2014; Shapiro, 2017). 
Travmatik bir olay yaşandığında, kişi yaşadığı anıyı olayın gerçekleştiği zamandaki duygu ve beden duyumları ile işlenmemiş bir şekilde kaydeder. Bu anılar diğer normal anılar gibi beyin tarafından hazmedilmediği için, en ufak bir tetikleyici ile karşılaşıldığında olay anındaki olumsuz duygu ve düşünceler tekrar tekrar ortaya çıkar (Duman, Bayram ve Demirtaş, 2018). EMDR hafizada işlevsel olmayan bir şekilde yanlış bir anı formunda depolanmış travmatik anının işlemlenmesini sağlayarak, travmatik anının oluşturduğu olumsuz etkilerin özümsenmesine yardımcı olur. (Kavakçı, 2014; Shapiro, 2018). Özellikle çocukluk çağında yaşanmış travmalar uyum sağlayacak şekilde işlenmeden depolanmışlardır. Kişinin şimdiki zamanda yaşadığı bozuklukların temelinde geçmişte yaşamış olduğu ve uyumlu bir şekilde işlenmeden depolanan travmatik deneyimler yatmaktadır (Kavakçı, Doğan ve Kuğu, 2010).

EMDR, diğer psikoterapi yöntemlerine göre travma sonrası stres bozukluğu belirtilerinin daha hızlı bir şekilde azalmasını sağlamaktadır. Yoğun bir rahatsızlık ile başvuran danışanlar daha ilk seanstan sonra rahatsızlıklarının hafiflemeye başladığını, rahatsız eden beden duyumlarının azaldığını, göz önüne gelen sahnelerde silikleşme veya uzaklaşmalar olduğunu söylemişlerdir. Üç ile beş EMDR seansından sonra travma sonrası stres bozukluğu tepkilerinde \%77-100 oranında azalma rapor edilmiştir (Kavakçı, 2014; Shapiro, 2017). Prozac verilen bir grupla EMDR uygulanan bir grup arasında yapılan karşılaştırmalara bakıldığında, sekiz ay sonra EMDR uygulanan grubun \%60'nın tamamen iyileştiği, Prozac alan grubun ise ilaç kullanmayı bıraktıktan sonra rahatsızlıklarının tekrar nüks ettiği görülmüştür (Van Der Kolk, 2019). Bu araştırma kapsamında EMDR ile ele alınmış bir travma yaşantısını içeren vaka ele alınmaktadır.

\section{YÖNTEM}

Araştırma EMDR yöntemi ile travma sonrası stres bozukluğu yaşayan bir bireyin olgu sunumunu kapsamaktadır.

\section{Olgu Sunumu}

Y Hanım 37 yaşında, kadın, doktor, on yıllık evli, iki çocuk annesi ve Büyükşehirde yaşıyor. Dış görünümü ve kişisel bakımı orta düzeyde, göz teması kuruyor, öfkeli, yüksek sesle konuşuyor ve çoğunlukla ağlıyor. Kederli ve çökkün görünüyor. Beş ay önce eşi tarafından aldatıldığını öğrenmiştir. Aldatılma durumunun yarattığı yıkıcı durum sebebi ile psikolojik desteğe başvurmuştur. Danışan ile görüşmeler, 2019 yılı sürecinde özel bir psikolojik danışma merkezinde gerçekleştirilmiştir. Toplam 10 seans süren görüşmelerde EMDR terapi yöntemi kullanılmış ve bu araştırmada ilk 5 görüşmeye yer verilmiştir. Görüşme kayıtları danışanın hiçbir şahsi bilgisini içermemekle birlikte, araştırma çalışması olarak yayınlanması için kendisinden izin alınmıştır. 


\section{EMDR Süreci}

1.seans: Bu seansta EMDR'nin birinci aşaması olan danışan geçmişi aşamasında danışanın öyküsü alındı. Y Hanım geceleri uyku sorunu yaşadığı, uykuya dalsa bile sürdürmekte zorluk çektiği, kâbuslar gördüğü, en ufak bir şeye karşı bile tahammülsüz olduğu, devamlı ağladığı, unutkanlıklar yaşamaya başladığı, olay aklına geldiğinde çarpıntı yaşadığı ve başının döndüğü, yemek yiyemediği ve fazlaca kilo verdiği şikâyetleri ile terapiye başvurmuştur. Y Hanım beş ay öncesine kadar bu sıkıntıları yaşamadığını ifade etmiştir.

Y Hanım, aldatıldığını, işyerine eşinin ilişki yaşadığı kişi tarafından gönderilen bir çiçek içerisinde mevcut mektupla öğrendiğini, bunu öğrendikten hemen sonra eşini aradığını, eşinin hemen kendisinin iş yerine geldiğini ve bu olay karşısında hiç tepki vermediğini, inkâr etmediğini ve her şeyi kabullendiğini paylaşmıştır. Y Hanım, kocasının bu durumu inkâr etmeyip kabullendiği anın bir türlü gözlerinin önünden gitmediğini, her gözünü kapadığında bu sahneyi hatırladığını bildirmiştir. Bu görüşmede Y Hanım ayrıca "kocasının işyerine giderek, kocasının ilişki yaşadığı kişiyle karşılaştığı” sahneyi, "işyerinin kapısında fenalaştığı ve güvenlik görevlilerinin kendisine müdahale ettiği” sahneyi devamlı hatırladığını söylemiştir. Bunun yanı sıra "evdeki dikiş makinesi", "karahindiba bitkisi”, beyaz BMW marka arabalar" "eşinin ona her sarılması" gibi, bu durumu hatırlamasına sebebiyet veren uyaranların, tetikleyicilerin olduğu tespit edilmiştir.

Y Hanım'ın köken aldığı aile ilişkileri ve çocukluk çağı yaşantıları hakkında bilgiler alınmıştır. Dört çocuklu bir ailenin ikinci çocuğu olduğunu, annesinin baskın, otoriter, eleştiren, küsme davranışı gösteren, sinirli bir yapısının olduğunu, babasının da pasif, edilgen, varlığı ile yokluğunun anlaşılmadı̆̆ı bir yapıda olduğunu ifade etmiştir. Çocukluğunda kendisinde iz bırakan büyük "T" olarak tanımlanan herhangi bir travma olmadığı, fakat annesinin kendisine ve kardeşlerine olan tavırlarını anımsadığında hala içinde hissettiği, tarif etmekte zorlandığı bir ürpermenin olduğundan bahsetmiştir. Tarif etmeye çalıştı̆̆ ilgisizlik, ihmal edilme, işgal edilme, değer ve takdir görememe gibi küçük “t” ler olarak tanımlanan travmalar ile ilgili olabileceği düşünülmüştür.

Danışan uykuya dalmakta ve uykuyu sürdürmekte güçlük yaşadığını, kocasının onu terk ettiğine dair kâbuslar gördüğünü, yaşadığı olayı devamlı Flashbackler halinde hatırladığını, en ufak bir şeye, çocuklarına sinirlenip aşırı tepkiler verdiğini, yapacağı işlerle ilgili unutkanlıklar yaşadığını, düşünce sürecinde dalıp dalıp gitmeler olduğunu, olayı her hatırladığında çarpıntı, baş dönmesi ve iştah azalması olduğunu söylemiştir. Danışanın klinik tablosu, klinisyen tarafından incelendiğinde DSM-V kriterleri doğrultusunda travma sonrası stres bozukluğu olarak değerlendirilmiştir.

2.seans: Bu seansta EMDR'nin ikinci aşaması olan hazırlık evresinde yapılması gerekenlere göre, danışana EMDR terapisinin ne olduğu, nasıl işlediğine dair bilgiler verilerek, yaşadığı bu olayla 
ilgili çalışmak için onay alınmıştır. Danışana, seans sırasında veya seanslar arasında yaşayabileceği sıkıntı verici malzemeyle baş edebilmesi için "Güvenli yer egzersizi” yapılmıştır.

Güvenli yer egzersizi, sekiz aşamada gerçekleşen bir prosedürdür. Danışandan kendisini sakin, güvende, huzurlu hissedebileceği, gerçekte var olan veya hayalinde canlandırabileceği bir yer bulması istenmiştir. Danışanın bu yeri düşünürken hissettiği olumlu, kendisine rahatlık veren duygu ve duyumları fark etmesi istendi ve sonra hissedilen bu olumlu duyumların iki yönlü uyarım ile işlemesi yapıldı. Danışana bu egzersizi kendi başına kaldığında ve bir sıkıntı hissettiğinde nasıl uygulayacağı anlatılmıştır.

3.seans: Danışan ile bu seansta klasik EMDR protokolünden farklı olarak, olay odaklı anlatım ve gtarama yöntemi kullanılmıştır. Standart protokolden farklı olarak danışanın tüm geçmiş anıları taranmadan sadece yakın zamanda olan travmatik olaydan itibaren öykü alınmaya ve çalışılmaya başlanmıştır. Yakın zamanda gerçekleșen travmatik olayın taranması ile rahatsızlık veren noktaların, sahnelerin bulunmasından sonra duyarsızlaştırma, yerleştirme, beden tarama, kapanış ve yeniden değerlendirme aşamaları ile devam edilmiştir. Bu aşamada danışana yüksek sesle olayın gerçekleştiği günden bugüne kadar neler olduğu anlattırılmıştır.

Terapist: "Şimdi sizden travmatik olayın gerçekleşmesinin kısa bir süre öncesinden başlayıp bugüne dek bütün travmatik olayı zihninizde canlandırmanızı istiyorum. Ayaklarınızın yere sağlam bastığını ve bu odanın güvenli bir yer olduğunu hissedin ve süreci yüksek sesle bana anlatın”. (Anlatma esnasında sürekli iki yönlü uyarım uygulanmıştır). Daha sonra ikinci kez aynı anlattırma (bu sefer konuşmadan içinden yaptırılarak) yapılarak onu rahatsız eden sahneler bulundu. Anlattırma esnasında danışanın dizlerine iki yönlü uyarım verilmiştir.

Terapist: "Şimdi yüksek sesle konuşmadan, (tıpkı bilgisayarda "google” üzerinden bir arama yapar gibi), bütün süreci zihninizde tarayın ve sizi rahatsız eden şeyleri, herhangi bir kronolojik siralama şartı olmaksızın, saptamaya çalışın. Travmanın gerçekleştiği andan şu ana dek tüm travmatik süreç içerisinde aklınıza gelen tüm her şeyi fark edin ve şu an hala size rahatsızlık veren herhangi bir şey saptadığınızda durun ve bana söyleyin".

Danışan "kocasının bu durumu inkâr etmeyip kabullendiği” sahnenin onu rahatsız ettiğini söylemesi üzerine bu sahnenin çalışılmasına karar verilmiştir. Seans süresi doksan dakika olarak belirlenmiştir. Üçüncü aşama olan değerlendirme aşamasına geçilmiştir.

Terapist: Şimdi kocanızın işyerinize geldiği, bu durumu inkâr etmeyip kabullendiği anı gözünüzün önüne getirmenizi istiyorum, bu anı gözünüzün önüne getirdiğinizde nasıl bir resim/sahne görüyorsunuz? 
Danışan: Eşimin bana hiçbir şey söylemeden tepkisizce, donuk gözlerle baktığı sahne.

Terapist: Şu anda o resme baktığınızda kendinizle ilgili olumsuz inancınız nedir? Bu sahne size kendiniz ile ilgili ne söylüyor?

Danışan: Değersizim. Eğer değerli olsaydım onun için bunu yapmazdı.

Terapist: Peki o resmi düşündüğünüzde kendinizle ilgili şu anda değersizim yerine neye inanmak isterdiniz? (Pozitif kognisyon belirlenmeye çalışılıyor)

Danışan: Değerli olduğuma inanmak isterdim.

Terapist: O resmi düşündüğünüzde değerliyim cümlesini bir ile yedi arasında ölçecek olsanız, bir tamamen yanlış ve yedi tamamen doğru olsa, şu anda ben değerliyim cümlesi size ne kadar doğru geliyor?

Danışan: 1. Yani tamamen yanlış geliyor. Olayı düşününce hiç değerli değilim.

Terapist: Peki o anı ve değerli olmadığınızı düşündüğünüzde şu anda hangi duyguları hissediyorsunuz?

Danışan: Korku, öfke

Terapist: Peki 0 ile 10 arası bir ölçekte "0” rahatsızlık yok veya nötr, "10” ise düşünebileceğiniz en yüksek rahatsızlık derecesi ise, bu olay şu anda sizi kaç derecesinde rahatsız ediyor?

Danışan: 9.

Terapist: Peki bu rahatsızlığı şu anda bedeninizde nerede hissediyorsunuz?

Danışan: Midemde

3.aşama olan değerlendirme aşaması tamamlandıktan sonra 4.aşama olan duyarsızlaştırma aşamasına geçilmiştir. Bu aşamada danışanı rahatsız eden sahne, bu sahneye ait danışanın kendisi hakkındaki olumsuz inancı ve duyguları ve beden duyumları ile birlikte çift yönlü uyarım verilerek duyarsızlaştırma yapılmıştır.

Terapist: Şimdi o resmi ve ben değersizim inancınızı aklınıza getirmenizi, hissettiğiniz korku, öfke duyguları ve bunların hepsini bedeninizde midenizde hissettiğinizi fark etmenizi ve parmaklarımı takip etmenizi istiyorum. (IYU)...

Terapist: Bırakın gitsin, derin bir nefes alın şimdi ne geldi?

Danışan: Midemdeki his yoğunlaştı.

Terapist: Peki buradan devam edin. (yaklaşık yarım dakika süren IYYU)...

Terapist: Şimdi ne geldi? 
Danışan: Bunu bana nasıl yapar diye düşündüm.

Terapist: Peki buradan devam edin. (IYY) ...

Terapist: Derin bir nefes alın. Şimdi ne geldi?

Danışan: Çok aşağılayıcı bir şey. Ona hiç yakıştıramıyorum.

Terapist: Peki buradan devam edin. (IYYU) ...

Terapist: Şimdi ne geldi?

Danışan: İçimde kaynayan bir şeyler var, çok öfkeliyim.

Terapist: Peki buradan devam edin. (IYYU) ...

Terapist: Şimdi ne geldi?

Danışan: Mektupta yazanlar, onunla her şeyimizi paylaşmış. Kadın bütün yaşantımızı biliyor hepsini yazmış bana.

Terapist: Peki buradan devam edin. (IYU) ...

Terapist: Şimdi ne geldi?

Danışan: Gittiğimiz tatillerdeki ayrıntıları bile biliyor, ne kadar yakınlarmış demek.

Terapist: Peki buradan devam edin. (IYYU) ...

Terapist: Şimdi ne geldi?

Danışan: Yatak odamızda ki tartışmamız. Çocuklar duydu hepsini.

Terapist: Peki buradan devam edin. (IYYU) ...

Terapist: Şimdi ne geldi?

Danışan: Ağlıyorum, beni sakinleştirmeye çalışıyor.

Terapist: Peki buradan devam edin. (IYYU) ...

Terapist: Derin bir nefes alın. Şimdi ne geldi?

Danışan: Beni ne kadar çok ağlatmış aslında.

Terapist: Peki buradan devam edin. (IYYU) ...

Terapist: Şimdi ne geldi?

Danışan: Ben aldattığını nasıl anlamam ama her zamanki gibi davrandı.

Terapist: Peki buradan devam edin. (IYYU) ... 
Terapist: Şimdi ne geldi?

Danışan: Öğrendiğim günün sabahı. Saçlarımı okşaması.

Terapist: Peki buradan devam edin. (IYYU) ...

Terapist: Şimdi ne geldi?

Danışan: Beni ne kadar çok sevdiğini söylemesi.

Terapist: Peki buradan devam edin. (IYYU) ...

Terapist: Şimdi ne geldi?

Danışan: Annemi düşündüm duysa acaba ne der diye.

Terapist: Peki buradan devam edin. (IYU) ...

Terapist: Şimdi ne geldi?

Danışan: Annemin aslında eşimi hiç istemediğini düşündüm. Bana layık bulmamıştı.

Terapist: Peki şimdi en baştaki resme tekrar odaklanır mısınız? Şu an da bu resim sizi ne kadar rahatsı ediyor? "0" ile "10" arasında bir puan verebilir misiniz?

Danışan: 6

Terapist: Peki şimdi o resme ve ben değersizim inancınıza, hissettiğiniz duygulara ve bedeninizde hissettiğiniz duyumlara tekrar odaklanmanızı istiyorum. (IYU) ... Şimdi ne var sizde?

Danışan: Midemdeki o kalkma hissi hafifledi, ama hala öfkeliyim.

Terapist: Peki bu duygunuzdan devam edin. (İYU)

Danışan: Artık ona nasıl güveneceğim bilmiyorum.

Terapist: Peki buradan devam edin. (IYYU)...

Terapist: Şimdi ne geldi?

Danışan: Sanki evin ortasına bomba düştü.

Terapist: Peki buradan devam edin. (IYY)...

Terapist: Şimdi ne geldi?

Danışan: Öğrendikten sonra onunla hemen işyerine gittik. Kadınla konuşuyorum.

Terapist: Peki buradan devam edin. (IYU)...

Terapist: Şimdi ne geldi?

Danışan: Kadının ne kadar bakımlı olduğunu düşündüm, herhalde bu haline âşık oldu. 
Terapist: Peki buradan devam edin. (IYU)...

Terapist: Şimdi ne geldi?

Danışan: Kadına zina davası açacağım dedim. Zina yok dedi.

Terapist: Peki buradan devam edin (IYY)...

Terapist: Şimdi ne geldi?

Danışan: Boğazım düğümlendi.

Terapist: Peki beden duyumunuzdan devam edin. (IYU)...

Terapist: Şimdi ne geldi?

Danışan: Düğümlenme devam ediyor.

Terapist: Peki devam edin. (IYYU)...

Terapist: Şimdi ne geldi?

Danışan: Biraz azaldı sanki. Annem bana bir şey söylediğinde de olurdu bu.

Terapist: Peki buradan devam edin. (IYYU)...

Terapist: Şimdi ne geldi?

Danışan: Anneme cevap veremezdik biz, hep sinirli olurdu.

Terapist: Peki beden duyumunuza odaklanır mısınız? (IYU)... Şimdi ne var?

Danışan: Dügümlenme yok şimdi.

Terapist: Güzel. Peki, şimdi en baştaki resme odaklanır mısınız? "0” ile "10" arası bir ölçekte, "0" rahatsızlık yok veya nötr, “10” düşünebileceğiniz en yüksek rahatsızlık derecesi ise, bu olay şu anda sizi ne kadar rahatsız ediyor?"

Danışan: 3

Terapist: Peki şimdi o resme ve ben değersizim inancınıza, hissettiğiniz duygulara ve bedeninizde hissettiğiniz duyumlara tekrar odaklanmanızı istiyorum. (IYYU)...

Terapist: Derin bir nefes alın. Şimdi ne geldi?

Danışan: Eşim ve çocuklarımı düşündüm.

Terapist: Peki buradan devam edin. (IYU)...

Terapist: Şimdi ne geldi?

Danışan: Çok kavga ettik bu olaydan sonra kapıya polis geldi. 
Terapist: Peki buradan devam edin. (IYY)...

Terapist: Şimdi ne geldi?

Danışan: Bizi herkese rezil etti, nasıl yaptı bunu.

Terapist: Peki buradan devam edin. (IYU)...

Terapist: Şimdi ne geldi?

Danışan: Düşünceli bir baba olsaydı bunu yapmazdı.

Terapist: Peki buradan devam edin. (IYY)...

Terapist: Şimdi ne geldi?

Danışan: Çocukları için yaptıkları aklıma geldi. Sabah kahvaltısında onların isteklerine göre yapar her şeyi.

Terapist: Peki buradan devam edin. (IYU)...

Terapist: Şimdi ne geldi?

Danışan: Umre'ye gittiğimiz, orada bana çay, kahve getirişi.

Terapist: Peki buradan devam edin. (IYYU)...

Terapist: Şimdi ne geldi?

Danışan: Aslında benimde her istediğimi yapar, bana değer verirdi.

Terapist: Peki buradan devam edin. (IYU)...

Terapist: Şimdi ne geldi?

Danışan: Bir şey yok.

Terapist: Peki şimdi en baştaki resme odaklanır mısınız? "0" ile "10" arası bir ölçekte, "0" rahatsızlık yok veya nötr, "10" düşünebileceğiniz en yüksek rahatsızlık derecesi ise, bu olay şu anda sizi ne kadar rahatsı ediyor?"

Danışan: Sahne silikleşti sanki, hızlandı, yakalayamıyorum. Bir an gelip geçiyor. Şu an rahatsız etmedi beni.

Terapist: Peki rahatsızlık düzeyinize bir puan verebilir misiniz?

Danışan: "0" diyebilirim. Çok ilginç.

Danışanın rahatsızlık düzeyi " 0 ” olduktan sonra EMDR'nin beşinci evresi olan yerleştirme evresine geçilmiştir. Yerleştirme aşamasında danışanın "değerliyim” olarak değişen pozitif kognisyonunun yerleştirmesi yapılmıştır. 
Altıncı evre olan beden tarama aşaması'nda danışanın beden taraması yapılmıştır. Daha önceden belirtmiş olduğu midesindeki kalkma hissinin olmadığı tespit edilmiş ve yedinci evre olan kapanış aşamasına geçilerek çalışma tamamlanmıştır.

4. seans: $\mathrm{Bu}$ seansta sekizinci evre olan yeniden değerlendirme aşaması gerçekleştirilmiştir. Danışan bir önceki seansa göre daha iyi olduğunu, o sahnenin bir daha hiç gözünün önüne gelmediğini, fakat sıkıntılarının kısmi olarak devam ettiğini söylemiştir. Bu seansta da danışana gtarama yapılmıştır.

Terapist: "Şimdi yüksek sesle konuşmadan, (tıpkı bilgisayarda "google” üzerinden bir arama yapar gibi), bütün süreci zihninizde tarayın ve sizi rahatsız eden şeyleri, herhangi bir kronolojik siralama şartı olmaksızın, saptamaya çalışın. Travmanın gerçekleştiği andan şu ana dek tüm travmatik süreç içerisinde aklınıza gelen tüm her şeyi fark edin ve şu an hala size rahatsızlık veren herhangi bir şey olup olmadığına bakın ve sizi rahatsız eden bir şey saptadığınızda durun.” G-Tarama esnasında sürekli İYU (iki yönlü uyarım) yapılmıştır.

Danışan daha önce "kocasının işyerine giderek, kocasının ilişki yaşadığı kişiyle karşılaştığı" sahnenin rahatsız ettiğini söylemiştir. $\mathrm{Bu}$ sahneye de değerlendirme aşamasında yapılması gerekenler yapılarak bu sahneyle ilgili olarak negatif kognisyon: güçsüzüm, rahatsızlık derecesi (SUD): 8, pozitif kognisyon: bununla baş edebilirim, pozitif kognisyona olan inanç düzeyi (VOC): 2 olarak belirlenmiştir. Beden duyumunun yeri ellerde, ayaklarda karıncalanma olarak tanımlanmıştır. Değerlendirme aşaması tamamlandıktan sonra duyarsızlaştırma aşmasına geçilerek çift yönlü uyarım ile işlenmeye başlanmıştır. Seans sonunda SUD düzeyi 0 olarak belirlenmiştir. Duyarsızlaştırma aşaması bittikten sonra yerleştirme aşamasına geçilmiştir. Seans sonunda olumsuz inanç olan "güçsüzüm”, "bununla baş edebilirim” olarak değişmiştir. VOC (olumlu inancın öznel değerlendirmesi): 7 olarak belirlendi. Beden taraması kontrol edildiğinde karıncalanmalar geçmişti.

5. seans: Danışan, başlangıç seansına göre çok daha iyi olduğunu kâbuslar görmediğini, ağlamaların kesildiğini bildirmiştir. Çalışılan sahnelerin gözünün önüne gelmediğini söylemiştir.

Tarama yapıldıktan sonra gözünün önünden gitmeyen sahnelerden biri olan "işyerinin kapısında fenalaştığı ve güvenlik görevlilerinin kendisine müdahale ettiği” sahnenin, en baştaki kadar onda rahatsızlık uyandırmadığını ifade etmiştir. İkinci seansta rahatsızlık derecesi (SUD): 9 olarak belirlenen sahnenin, rahatsızlık derecesinin diğer anılar çalışıldıktan sonra 5'e düştüğü tespit edilmiştir. Bu sahneyle ilgili olarak N.K: kontrol bende değil P.K: kendimi kontrol edebilirim, olayın rahatsızlık derecesi (SUD): 5, pozitif kognisyon (VOC): 1 olarak belirlenmiştir. Beden duyumunun yeri ise göğüste sıkışma hissi olarak tanımlanmıştır. Seans süresi doksan dakika olarak belirlenerek, anının işlemlenmesi gerçekleştirilmiştir. 
Seansın sonunda olumsuz inanç olan "kontrol bende değil", "kendimi kontrol edebilirim" olarak değişmiştir. (SUD): 0 ve (VOC): 7 olarak belirlenmiştir. Beden taraması yapıldığında herhangi bir rahatsızlık bildirilmemiştir. Yerleştirme seansı yapılarak bitirilmiştir.

Danışan bir sonraki seansa geldiğinde çalışılan sahnelerin artık onu rahatsız etmediğini, ağlama nöbetlerinin büyük oranda azaldığını, kabuslar görmediğini, uykularının daha iyi olduğunu, iştahının eskisine yakın oranda açıldığını, konsantrasyon düzeyinin artış gösterdiğini söylemiştir.

Danışanın klinik tablosuna bakıldığında başlangıca göre travma sonrası stres bozukluğu belirtilerinde \%60 düzeyinde iyileşmeler saptanmıştır. Danışanla EMDR seanslarının devam etmesine ve yaşadığı travmatik yaşantıyla ilgili belirlenmiş olan tetikleyicilerin ve çocukluk travmalarının da tespit edilip çalışılmasına karar verilmiştir. Sonra ki seanslarda anının tekrar hatırlanmasına sebebiyet veren diğer uyaranlar yani tetikleyiciler çalışılmıştır. Toplam on seans süren EMDR terapileri sonucunda danışanın TSSB belirtilerinde \%80 oranında iyileşme gözlemlenmiştir.

Danışanla yaşanılan travmaya dair yapılan çalışmalar sonrasında devam eden sıkıntıların, danışanın erken çocukluk dönemine ve geçmiş yaşantısına dair olan küçük " $t$ ” ler ile ilgili olduğu düşünüldüğünden, bu yaşantılarına dair anı taramaları yapılarak, annesi ve babasıyla olan ilişkilerine dair, hatırladığında kendisini rahatsız eden ve bir takım olumsuz bilişlerinin olduğu anılar saptanarak çalışılmaya devam edilmiştir. Bu anıların çalışılması sonrasında danışanın TSSB belirtilerinin tamamen ortadan kalktığı görülmüştür.

\section{TARTIŞMA VE SONUÇ}

Araştırmanın temel amacı, EMDR yönteminin çift ilişkisinde aldatılma ile ortaya çıkan travma sonrası stres tepkileri üzerindeki etkisini incelemektir. Yakın zamanda yapılan çalışmalar ilişki sorunlarında yaşanılan deneyimlerin fazla miktarda travma sonrası stres bozukluğu belirtisi ortaya çıkardığını göstermektedir (Shapiro, 2018; s:16). Bu çalışmada sunulan olguda da kocası tarafından aldatılan Y Hanım'da uyku sorunları, kabuslar görme, iştahsızlık, tahammülsüzlük, uyaranlar karşısında aşırı tepki verme, öfke, ağlama nöbetleri, unutkanlık gibi travma sonrası stres bozukluğu tepkileri görülmüştür. Bu olgu üzerinde yapılan çalışmadan elde edilen bulgulara göre EMDR yöntemi uygulandıktan sonra olgunun travma sonrası tepkilerinde büyük oranda iyileşme meydana geldiği görülmüştür.

Yapılan çalışmalar çiftlerin yardım almak için bir uzmana başvurduklarında yaşanılan iki sorunun terapinin çoğunlukla başarısız olmasına sebep olduğunu göstermektedir. Bunlardan biri fiziksel şiddet, diğeri de aldatma-aldatılma olayıdır. Aldatma durumunda aldatılan eşin, kocasının/karısının diğer kişiyle ilişkisini öğrendiğinde hissedeceği duygular aşağılanma, yetersizlik, değersizlik, 
haksızlığa uğramışlık vb. olmaktadır. Duruma dikkatlice bakıldığında aslında bunların bir psikolojik şiddet olarak algılandığı görülmektedir (Hasanoğlu, 2013; s.99). Bunun yanı sıra yaşanılan travmatik olay bireyde "yetersizim”, “değersizim”, "kontrol bende değil”, “tehlikedeyim”, "güçsüzüm” gibi olumsuz bilişlere sebebiyet vermektedir (Kavakç1, 2014; s:154). $\mathrm{Bu}$ çalışmada Y Hanım, yaşamış olduğu bu travmatik yaşantıyı psikolojik bir şiddet olarak algılamıştır. Bunun yanı sıra gözünün önüne gelen sahneler ile ilgili danışanın "ben değersizim”, "güçsüzüm”, "kontrol bende değil” şeklinde olumsuz inançlara sahip olduğu görülmüş olup, EMDR terapi yöntemi ile danışanın bu olumsuz inançları yeniden işlenerek olumlu inançlara dönüştürülmüş ve yerleştirilmiştir.

EMDR seanslarında travmatik yaşantıya dair bir anı ile çalışıldığında, onunla bağlantılı olan diğer anılarında bundan olumlu etkilenmesi beklenmekte ve rahatsızlık dereceleri kendiliğinden düşebilmektedir (Shapiro, 2018). Bu olguda da birinci ve ikinci anı ile çalışıldıktan sonra, üçüncü anının daha önceden dokuz olarak belirlenen rahatsızlık düzeyinin beşe düştüğü görülmüştür.

Yapılan çalışmalar 3 ile 5 arasında yapılan EMDR seanslarından sonra TSSB belirtilerinde \%77100 oranında iyileşmeler olduğunu söylemektedir. (Shapiro, 2017). Bazı durumlarda semptomlarda değişiklik olmayabilir veya semptomlar tamamen ortadan kalkmayabilir. Bu durumda işlenmemiş başka anıların varlığından şüphe duymak gerekir. Yaşanılan son olay daha önceki işlenmemiş anıları da tetikleyebilir. Kişinin hayatında mutsuzluk ve acı çekmesinin sebebi olan 10 ile 20 arasında işlenmemiş anının varlığından söz edilmektedir (Kavakçı, 2014; Shapiro, 2018). Bu olguda, danışanın yaşadığı olumsuz yaşantıya dair, gözünün önüne gelen sahneler ve olayı devamlı hatırlatan uyaranlar yani tetikleyiciler ile toplam 10 seans EMDR yöntemi ile çalışılmıştır. Yapılan EMDR seansları sonrasında danışanın 5 aydır devam eden TSSB belirtilerinde \%80 oranında azalma olduğu gözlenmiştir.

Travma çalışılırken ilk önce sel, deprem, tecavüz, taciz, saldırı vb. gibi büyük "T" olarak adlandırılan travmatik yaşantılar öncelikli olarak çalışılmaktadır. Tedavinin tam anlamıyla başarılı olabilmesi için, bunlar kadar önemli olan, çocuklukta yaşanmış, kişinin hayatında işlev bozukluklarına neden olan ve küçük " $\mathrm{t}$ " olarak adlandırılan, olumsuz inançların gelişmesine sebebiyet veren bir takım olumsuz yaşantıların da çalışılması gerekmektedir (Kavakçı, 2014). Bu olguda da danışanın travmatik yaşantısıyla ilgili olarak gözünün önüne gelen üç sahne ile ilgili çalışıldıktan sonra TSSB belirtilerinde \%60 azalma görülmüştür. Ardından tetikleyiciler ile yapılan çalışmalar sonrasında TSSB belirtilerinin \%80 oranında azaldığı görülmüştür. Dolayısıyla travmatik yaşantıya ait anıların ve tetikleyen unsurların çalışılmasından sonra dahi travma sonrası stres bozukluğu belirtilerinin tamamen bitmemiş olması, danışanın erken çocukluk yaşantısına dair başka olumsuz yaşantılarının da olabileceğinin düşünülmesini gerektirmiştir. Geriye dönük yapılan anı 
taramalarında danışanın özellikle annesiyle olan yaşantılarında danışanın kendisini değersiz biriyim, çaresizim ve güçsüzüm şeklinde tanımladığı birtakım anıların olduğu tespit edilmiştir. $\mathrm{Bu}$ yaşantıların, bu olumsuz inançlar ile birlikte hatırlanıyor olması ve rahatsızlık veriyor olması bugüne kadar yanlış bir formda saklandığını göstermektedir. Danışanın çocukluğuna ait olan bu olumsuz yaşantıları da EMDR yöntemi ile bir süre daha çalışıldıktan sonra travma sonrası stres bozukluğu belirtilerinin tamamen ortadan kalktığı görülmüştür.

$\mathrm{Bu}$ olgu çalışması sonucunda ilişki sorunlarının özellikle aldatılmanın eş üzerinde yaratmış olduğu travma sonrası stres bozukluğu belirtilerinin EMDR yöntemi ile başarılı bir şekilde tedavi edildiği sonucuna varılmıştır. Kuşkusuz tek bir olgunun başarılı bir şekilde sonuçlandırılmış olması, EMDR'nin aldatılma sonucunda ortaya çıkan travma sonrası stres bozukluğunun tedavilerinin genelinde etkili bir yöntem olduğu çıkarımında bulunmayı mümkün kılmamaktadır. Bunun için daha fazla araştırma ile bu alanın desteklenmesi faydalı olacaktır. Literatür taramalarında bu çalışmayı destekleyecek başka herhangi bir araştırmaya rastlanmamıştır, bu durum yapılan bu çalışmanın ilk olması bakımından örnek teşkil etmesini sağlarken, alanda daha fazla çalışma yapılması ihtiyacını da göstermektedir. Tüm bu kısıtlılıklara rağmen başarılı bir şekilde sonuçlandırılmış bu olgunun, diğer alan çalışanlarına bu tür ilişki sorunlarıyla çalışırken yol gösterici olacağı düşünülmektedir. Sonuç olarak, travma sonrası stres bozukluğunda EMDR tedavisinin hem etkili hem güçlü hem de kısa süreli bir terapi yöntemi olması travma yaşamış kişilerde iyi bir seçenek olduğunu göstermiştir. 


\section{KAYNAKÇA}

Bolu, A., Erdem, M. ve Öznur, T. (2014). Travma sonrası stres bozukluğu. Anatol J Clin Investig, 8(2), 98-104.

Cori, J.L. (2018). Bağlanma: İlk temelimiz. Annenin duygusal yokluğu içinde (s.71-96). (B. Haktanır, Çev.). İstanbul: Koridor Yayıncılık.

Duman, R.N., Bayram, S. ve Demirtaş, B. (2018). EMDR: Olgu sunumları. Türkiye Bütüncül Psikoterapi Dergisi,1(1), 142-164.

Ehlers, A. ve Clark, D. M. (2000). A cognitive model of posttraumatic stress disorder. Behaviour Research and Therapy, 38(4), 319-345.

EMDR Derneği. (2018). EMDR nedir? 15 Kasım 2019 tarihinde, http://www.emdr-tr.org/emdrnedir adresinden erişildi.

Hasanoğlu, A. (2013). Hayır beni aldattı̆ğını bilmek istemiyorum. E. Duru (Der.), İlişkilerin günlük hayatı içinde (s.99-102). İstanbul: Remzi Kitabevi.

Hasanoğlu, A. (2018). Bireysel ve toplumsal travma. O.Kaya (Der.), Hayat ve diğer hastalıklar içinde (s:35-41). İstanbul: Doğan Egmant Yayıncılık.

Karaoğlu, A.B. (2016). TSSB ve depresyon arasındaki ilişkide ontolojik iyi oluşun aracılık etkisi: Bir yapısal eşitlik modellemesi çalışması. Yayımlanmamış yüksek lisans tezi. İstanbul Arel Üniversitesi Sosyal Bilimler Enstitüsü, İstanbul.

Kavakçı, Ö., Doğan, O. ve Kuğu, N. (2010). EMDR: Psikoterapide farklı bir seçenek. Düşünen Adam Psikiyatri ve Nörolojik Bilimler Dergisi, 23(3), 195-205.

Kavakçı, Ö. (2014). Ruhsal travma tedavisi için EMDR. Ankara: HYB Basım Yayın.

Shapiro, F. (2017). EMDR Göz hareketleriyle duyarsızlaştırma ve yeniden işleme, temel prensipler, protokoller ve prosedürler. (M. Şaşzade ve I. Sansoy, Çev.). İstanbul: Okuyan Us Yayın.

Shapiro, F. (2018). EMDR terapisi teknikleri ile acı anıları silmek. (F. Gülfidan, Çev.) İstanbul: Kuraldışı Yayıncılık.

Van Der Kolk, B.A. (2019). Beden Kayıt Tutar: Travmanın iyileşmesinde beyin, zihin ve beden. (N.C. Maral, Çev.). Ankara: Nobel Akademik Yayıncılık. 